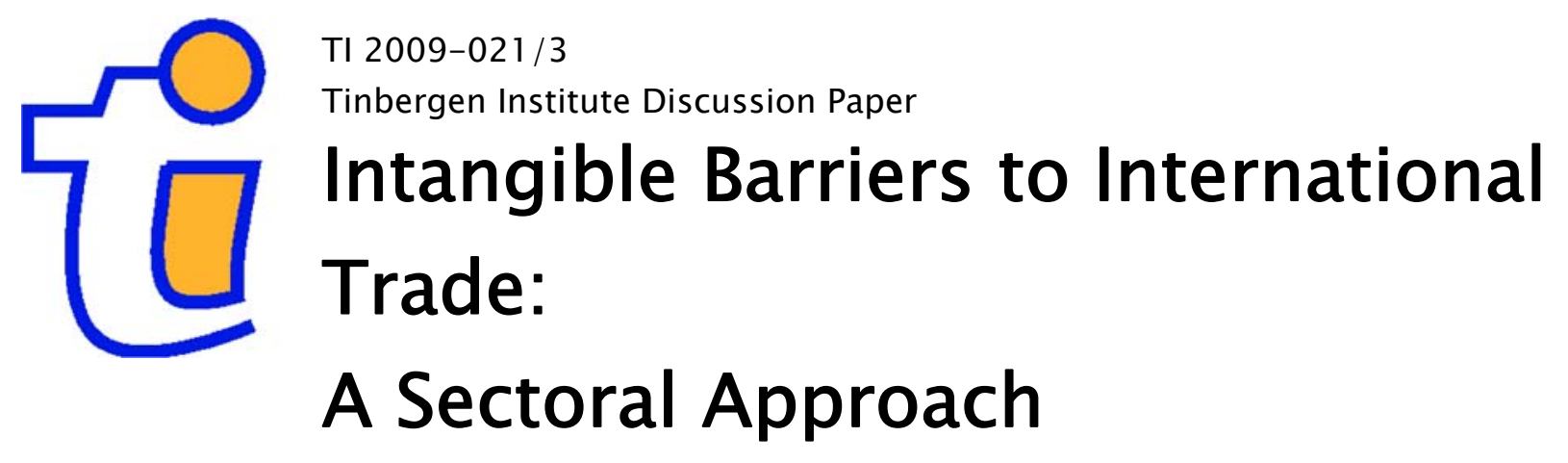

\author{
Jan MöhImanna,b \\ Sjef Ederveenc \\ Henri L.F. de Groota,b,d \\ Gert-Jan M. Lindersa
}

\footnotetext{
a Dept. of Spatial Economics, Faculty of Economics and Business Administration, VU University Amsterdam;

${ }^{b}$ CPB Netherlands Bureau for Economic Policy Analysis, The Hague;

'Ministry of Economic Affairs, The Hague;

d Tinbergen Institute.
} 


\section{Tinbergen Institute}

The Tinbergen Institute is the institute for economic research of the Erasmus Universiteit Rotterdam, Universiteit van Amsterdam, and Vrije Universiteit Amsterdam.

Tinbergen Institute Amsterdam

Roetersstraat 31

1018 WB Amsterdam

The Netherlands

Tel.: +31(0)205513500

Fax: $+31(0) 205513555$

Tinbergen Institute Rotterdam

Burg. Oudlaan 50

3062 PA Rotterdam

The Netherlands

Tel.: + $31(0) 104088900$

Fax: $+31(0) 104089031$

Most TI discussion papers can be downloaded at http://www.tinbergen.nl. 


\title{
Intangible barriers to international trade: A sectoral approach
}

\author{
Jan Möhlmann ${ }^{\mathrm{a}, \mathrm{b}}$, Sjef Ederveen ${ }^{\mathrm{c}}$, Henri L.F. de Groot ${ }^{\mathrm{a}, \mathrm{b}, \mathrm{d}}$ and Gert-Jan M. Linders ${ }^{\mathrm{a}, 1}$ \\ ${ }^{a}$ Department of Spatial Economics, VU University Amsterdam \\ ${ }^{\mathrm{b}}$ CPB Netherlands Bureau for Economic Policy Analysis, The Hague \\ ${ }^{c}$ Ministry of Economic Affairs, The Hague \\ ${ }^{\mathrm{d}}$ Tinbergen Institute, Amsterdam-Rotterdam
}

\begin{abstract}
This paper studies the importance of intangible barriers to trade in explaining variation in disaggregate international trade. The analysis is based on a sample of 55 countries for the year 2000. We explicitly focus on the importance of institutional and cultural dimensions of distance. Our results reveal there is substantial heterogeneity in the impact of intangible barriers for different product groups. More specifically, we find that cultural differences do not affect total trade significantly, whereas trade in homogeneous goods is significantly negatively affected. A possible explanation for this pattern is that the substitution effect between trade and FDI is stronger for more differentiated products.
\end{abstract}

JEL code: F14

Keywords : bilateral trade, gravity model, intangible barriers, cultural distance, sectoral trade

\footnotetext{
${ }^{1}$ Corresponding author: Henri L.F. de Groot, VU University Amsterdam, Department of Spatial Economics, De Boelelaan 1105, 1081 HV Amsterdam, The Netherlands, tel: +31 20598 6168, fax: +31 20598 6004, email: hgroot@feweb.vu.nl. We are grateful to Andrés Rodríguez-Pose and participants of the 2007 conference "The Gravity Equation - Or: Why the World is Not Flat" in Groningen for useful comments on an earlier version of this paper. The usual disclaimer applies.
} 


\section{Introduction}

International trade flows have increased impressively in the last few decades. Data from the United Nations, which have been edited by Feenstra et al. (2005), suggest that the aggregate nominal value of reported international trade increased from about 130 billion USD in 1962 to more than 6.5 trillion USD in 2000. This corresponds to an annual growth rate close to $11 \%$. With an estimated world population of about 6 billion in 2000, this implies that international trade per capita was over 1,000 USD or about $15 \%$ of the average Gross Domestic Product (GDP) per capita.

The growing importance of international trade has led to an increased need for sound analyses of its determinants. The gravity model has been the workhorse model to explain international trade flows for nearly half a century now. The main idea behind this model is that the magnitude of bilateral trade flows can be explained by the economic size of the two trading countries and the distance between them (Deardorff, 1998). The model has sound theoretical foundations, yields almost invariantly plausible parameter estimates and has a strong explanatory power.

Although the basic framework of the gravity model is unaltered throughout the years, new insights have contributed to its increasing popularity by improving its theoretical underpinnings (see, e.g., Feenstra, 2004) and addressing econometric issues concerning the correct specification of the model (see, e.g., Anderson and Van Wincoop, 2004). These include the correct specification of the multilateral resistance (price) effect, the specification of panel gravity equations and the treatment of zero-valued bilateral trade flows.

Despite the rapid growth of trade and the popular discussions on the "death of distance' (e.g., Cairncross, 1997; Friedman, 2005), many studies estimating gravity equations of bilateral trade confirm that the impact of geographic distance is still large and has not shown a clear tendency to decline over time (e.g., Linders, 2006; Disdier and Head, 2008). Thus, distance still matters for the patterns of trade. Given the decline in transport and communication costs over time, this finding provides support for the view that intangible trade barriers are persistent and are important in explaining the resistance to trade (Obstfeld and Rogoff, 2000; Anderson and Van Wincoop, 2004).

Substantiating the effect of intangible trade barriers has been another important recent extension of the gravity model. Most of the early gravity model studies consider only geographical distance. However, it is likely that there are significant additional costs involved in trading besides transport costs. Deardorff (2004) suggests that the current amount of global trade is far below the level that would prevail if transport costs were the only costs of trading. 
Furthermore, Trefler (1995) and Davis et al. (1997) find that the factor proportions theory of trade would predict trade flows that are missing from actual observations. They argue that home bias in preferences may explain this 'mystery of missing trade'. The missing trade flows might partly originate from alternative dimensions of distance in trade. These other dimensions of distance could include cultural and institutional distances. Den Butter and Mosch (2003) and Anderson and Van Wincoop (2004) state that the transaction costs of trading can include many aspects including transport costs, tariffs, search costs, information costs regarding the product and the reliability of the trading partner, and contract enforcement costs. These transaction costs are likely to increase with the cultural gap between countries because firms will have less knowledge about foreign cultures and markets. Moreover, the costs of negotiation will be higher when the trading partners do not speak the same language (cf. Anderson and Marcouiller, 2002). This is why more recent studies include measures for cultural and institutional distance (see, for example, Den Butter and Mosch, 2003; De Groot et al., 2004; Linders et al., 2005) in their gravity model specifications.

What has remained unchanged in the application of the gravity model is the strong focus on total trade flows. This is surprising, as there are good reasons to believe that the effects of distance and GDP on the value of bilateral trade differ between different product groups. An important exception is the seminal study by Rauch (1999) in which a network/search view of international trade is developed. He argues that search costs present a major barrier to trade in differentiated products, whereas distance only increases transport costs for trade in homogeneous products without principally preventing trade. These hypotheses are empirically tested by estimating models for both homogeneous and heterogeneous products, providing empirical support for the hypotheses.

In this study we build on the work of Rauch (1999) by estimating the gravity model for different product groups. We improve and extend his empirical work in a number of directions. First, we incorporate new econometric insights. More specifically, we use the Heckman selection model to estimate the gravity equation. This model is able to deal with zero trade flows in a more satisfactory way, which becomes particularly relevant when studying disaggregate trade because of the increased absence of trade of specific products between pairs of countries. Second, we use a broader view on the different dimensions of distance. Rauch (1999) hypothesises that networks are an important factor in trade transactions. and that a common language or a shared colonial history will make networks more likely to exist. Besides geographical distance, Rauch uses a dummy variable indicating whether two countries share a common language or a shared colonial history to test this view. 
However, this variable does not capture the idea that transaction costs increase when firms have less knowledge about foreign cultures and markets due to cultural differences. In this study we include additional cultural indicators to test this hypothesis as well. Third, we explore the importance of using different product categories for the parameters of the gravity equation. For that purpose we extend the analysis of Rauch by exploring the impact on different sectors of the economy and on specific products. In addition we use data covering a more recent time period (viz. 2000).

The remainder of this paper is organised as follows. The next section discusses the basic concept of the gravity model for bilateral trade. Section 3 elaborates on the importance of intangible barriers to trade, with a special focus on cultural and institutional distance. Data and estimation method are discussed in Section 4. Section 5 presents the results. This section consists of three parts. The first part strictly follows the distinction made by Rauch (1999) between homogeneous and heterogeneous products and considers the impact of more recent data and different estimation techniques on the key results obtained by Rauch. The second part focuses on the importance of intangible barriers to trade. The last part applies the gravity model to more detailed product groups. Finally, section 6 presents the conclusions and provides some further discussion.

\section{The gravity model in international trade}

The gravity model of bilateral trade has become the workhorse model of applied international economics (Eichengreen and Irwin, 1998). It was originally inspired by Newton's gravity equation in physics, in which the gravitational forces exerted between two bodies depend on their mass and distance. The basic idea of gravity can be used to model spatial interaction in social sciences as well. The gravity model has been used extensively in regional science to describe and analyse spatial flows of information, goods and persons (see, e.g., Greenwood, 1975; Nijkamp and Reggiani, 1992; Isard, 1999), and was pioneered in the analysis of international trade by Tinbergen (1962), Pöyhönen (1963) and Linnemann (1966).

The traditional gravity model relates bilateral trade flows to the GDP levels of the countries and their geographic distance. The levels of GDP reflect the market size in both countries, as a measure of 'economic mass'. The market size of the importing country reflects the potential demand for bilateral imports, while GDP in the exporting country represents the potential supply of goods from that country; geographic distance reflects resistance to bilateral trade. The familiar functional form from physics is then used to relate bilateral trade to these variables of economic mass and distance. 
Usually, the gravity equation is expressed in logarithmic form, for the purpose of empirical estimation. The basic gravity equation, used in estimation, then looks as follows:

$$
\ln T_{i j}=\ln K+\alpha \ln Y_{i j}+\beta \ln y_{i j}+\lambda \ln D_{i j}+\delta M_{i j}+\theta_{1} C D_{i j}+\theta_{2} I D_{i j}+\varepsilon_{i j}
$$

where $T_{i j}$ stands for exports from country $i$ to country $j ; K$ is a scalar; $Y_{i j}$ and $y_{i j}$ represent the product of GDP and GDP per capita of country $i$ and $j$; and $D_{i j}, C D_{i j}$ and $I D_{i j}$ reflect physical, cultural and institutional distance between the countries. The matrix $M_{i j}$ contains additional variables that may affect the ease of trading bilaterally, such as a common border, linguistic or colonial links, and common trade bloc membership (such as the EU and NAFTA). In specifying this basic structure of the model, we largely follow the model set out in Rauch (1999). In estimating the model, we conform as much as possible to the country sample of Rauch (1999). This serves to facilitate the comparison of results. Our key parameters of interest are $\theta_{1}$ and $\theta_{2}$ capturing the effect of, respectively, cultural and institutional distance on trade. Finally, $\varepsilon_{\mathrm{ij}}$ is a disturbance term that reflects the impact of other factors (assumed orthogonal) that have not been included in the model.

The recent literature has provided extensions to the theoretical foundations of the gravity model (see, for example, Anderson and Van Wincoop, 2003; Feenstra, 2004; Anderson, 2007). This has resulted in a modification of the gravity equation (1), to account for omitted variable bias related to the omission of multilateral resistance terms $P_{i}$ and $P_{j}$, which are themselves a function of all regressor variables (e.g., $Y_{k}, Y_{l}, M_{k l}$ and $D_{k l}$ ) for all countries $k$ and $l$.

The resulting equation, also indicated as the theoretical gravity equation, is of the form:

$$
\ln T_{i j}=\ln K+\alpha \ln Y_{i j}+\beta \ln y_{i j}+\lambda \ln D_{i j}+\delta M_{i j}+\theta_{1} C D_{i j}+\theta_{2} I D_{i j}-\ln P_{i}^{1-\sigma}-\ln P_{j}^{1-\sigma}+\varepsilon_{i j}
$$

where $\sigma$ stands for a preference parameter (in the theoretical derivations equal to the elasticity of substitution between goods from different countries). Because the logged multilateral resistance terms are non-linear functions of the variables and parameters in the model, this gravity equation cannot be estimated by OLS. A number of solutions has been proposed for estimation. In our analysis, we will proceed in line with Feenstra (2004) to estimate a gravity equation in which the multilateral resistance terms are estimated as country-specific fixed 
effects. We assume that trade costs are symmetric, implying that we assume the existence of a single country-specific multilateral resistance term for each country. ${ }^{2}$

\section{Multidimensional distance: institutions, culture and trade}

The point of departure for our analysis is the observation that trade costs are important to understand the patterns of bilateral trade. Bilateral resistance to trade can arise from formal barriers (tariffs, NTBs) and transport costs, but also from informal barriers such as differences in institutional quality and in cultural norms and values. Moreover, these barriers to trade may be more important for some products than for others. This paper focuses on these intangible barriers to trade, and asks the question: 'Do institutional and cultural distance affect trade differentially across different (groups of) products?'

\subsection{The network view on trade}

To understand how trade patterns evolve, recent research points at the importance of networks, rather than atomistic markets (e.g., Rauch, 1999; 2001). The search/network view starts from the observation that a majority of products is not traded on organized exchanges. Therefore, search processes are important in order to match buyers and sellers. Networks serve to facilitate the search for suitable trade partners. As a result, understanding the characteristics and development of networks is important to explain the observed patterns of trade.

Rauch (1999) classifies products according to product type. Homogeneous products differ from differentiated goods in the use of 'markets' as opposed to 'networks' for exchange. Homogeneous goods can be compared exclusively on the basis of price differences. Several homogeneous products are traded on an organized exchange where supply and demand directly confront and match. Many other homogeneous products are sold on a decentralized market where the 'invisible hand' of the price mechanism takes care of coordination. Although not frictionless, matching resembles a perfectly competitive centralized market, where the comparison is based on prices as the only relevant characteristic. For these products, reference prices are often published, illustrating that the price mechanism guides allocation through the possibility for international arbitrage of price differences. Differentiated products cannot be compared on the basis of prices alone. Price differences

\footnotetext{
${ }^{2}$ Allowing for asymmetric trade costs, hence different multilateral resistance terms for exports and imports, does not lead to major changes in the OLS estimation. With the Heckman selection model we had to rely on a single indicator of multilateral resistance per country for technical reasons, since a solution could not be reached otherwise.
} 
must be adjusted for differences in characteristics and quality between the varieties. The relative importance of the various characteristics differs across countries depending on the available supply and preferences that prevail (Rauch, 1999). In the end, each variety has its own unique blend of characteristics. The product is 'branded', and has its own supplier. Because of the difficulty of comparing differentiated products, differentiated products cannot be traded on organized exchanges. Moreover, information costs are so high that international arbitrage by specialized traders across varieties is not feasible either. Instead, differentiated products are traded through networks by search and match between traders, customers and suppliers. Rauch (1999) argues that the process of search is facilitated by factors that improve the information flow and knowledge of foreign markets. He refers to shared language, colonial links and geographical proximity as search-enabling factors, because they increase bilateral familiarity and decrease 'psychic distance' (see Frankel, 1997).

Rauch (1999) identifies three product groups that reflect the 'network versus market' distinction in trade. Homogeneous products comprise two groups: products traded on an organized exchange and reference-priced articles; the third group consists of differentiated goods. The network theory of trade hypothesizes that search costs are most important for the pattern of trade in differentiated products and least important for organized-exchange products.

\subsection{Insecurity of property and trade}

An alternative explanation for unobserved trade costs focuses on variation in institutional effectiveness across countries. A poor institutional environment, in terms of property rights protection and contract enforceability, entails negative externalities for private transactions and consequently raises transaction costs. As a result, the quality of governance is an important determinant of economic growth and development (see, e.g., Olson, 1996). Institutional economics has recently been extended into the field of international economics (e.g., Wei, 2000; Anderson and Marcouiller, 2002; Dixit, 2004). This approach states that insecurity of property and contract enforcement imposes high costs on trade. Rodrik (2000) argues that the transaction-costs problem of contract enforcement is aggravated for international trade, compared to domestic exchange. International trade involves at least two jurisdictions, which makes contract enforcement more difficult. This discontinuity in the political and legal system increases uncertainty and the risk of opportunistic behaviour by either party to the exchange. Accordingly, differences in the effectiveness of legal and policy systems in providing law and order, securing contract enforcement and facilitating trade is an 
important determinant of bilateral trade costs. Besides the level of the quality of institutions, the similarities of institutions between two countries could also affect bilateral trade costs. With more similar institutions enforcement of international contracts is easier and uncertainty is reduced (see, for example, De Groot et al., 2004).

In this paper, we investigate whether the impact of differences in institutional quality on bilateral trade depends on the type of product that is being traded. We would generally expect the costs of insecurity and differences in contract enforceability to be lowest for organized-exchange products. Specialized traders can diversify systemic risk of opportunistic behaviour by ordering from many different suppliers, without any concern left for final customers. For reference-priced commodities, the need for more case-specific search raises search costs and creates an incentive to enter into closer relations. Trade will increasingly avoid environments with very different institutional settings. The largest effect is expected for trade in differentiated goods.

\subsection{Cultural differences as trade barrier}

Many studies have extended the basic trade-flow gravity equation with (dummy) variables indicating whether the trading partners share a common language, religion, and/or colonial past (e.g., Geraci and Prewo, 1977; Frankel, 1997; Boisso and Ferrantino, 1997; Yeyati, 2003; Guiso et al., 2004). Most studies find that these variables have significantly positive effects on the magnitude of international trade flows. Although this indicates that these variables matter, they only capture cultural familiarity, in the sense that the trading partners will have more knowledge of each others culture and will find it easier to communicate and share information (Rauch, 1999; 2001).

We go beyond cultural familiarity by focusing on cultural distance, which is defined as the extent to which the shared norms and values in one country differ from those in another (Kogut and Singh, 1988; Hofstede, 2001). It is generally acknowledged that a large cultural distance raises the costs of international trade, as large cultural differences make it difficult to understand, control, and predict the behaviour of others (Elsass and Veiga, 1994). This complicates interactions (Parkhe, 1991), thus impeding the realization of business deals. Some of the most notable difficulties associated with cross-cultural interaction include those associated with understanding, and particularly those associated with differences in perceptions of the same situation. Differences in perceptions complicate interactions, make them prone to fail, and hinder the development of rapport and trust - factors that generally 
facilitate the interaction process and lower the costs of trade (Neal, 1998). This suggests that a large cultural distance between countries reduces the amount of trade between them.

However, cultural differences can also have a positive impact on trade. When entering foreign markets, companies have to decide whether to export products to another country or open a factory to start local production. The trade-off between producing locally and producing at a single site to benefit from scale advantages is known as the proximityconcentration trade-off. The literature on trade and horizontal foreign direct investment (FDI) suggests that the trade off between various modes of serving foreign markets may result in a positive effect of cultural and institutional distance on trade (Brainard, 1997; Helpman et al., 2004). An increase in cultural distance is likely to raise the costs of bilateral FDI more than the costs of bilateral trade, because FDI involves a higher stake in the local foreign market. Resource commitment, in the form of asset specific investments, is higher for FDI than for trade. Moreover, cultural differences are likely to affect the variable costs of direct local presence via FDI more than the cost of trading, as the transaction costs of managing and producing locally are relatively more substantial. If the costs resulting from cultural differences rise, companies may therefore prefer to focus on exports rather than FDI. This may lead to a substitution of local presence by trade. The total effect of cultural distance on trade then consists of a direct, negative effect and a positive substitution effect from FDI to trade. The total effect could therefore be either positive or negative. ${ }^{3}$

Cultural diversity can also have a positive influence on international trade through specialisation. Wherever there are big differences between countries, there are larger opportunities for specialising in the production of specific goods, which can be exchanged via international trade. In the end, the effect of cultural distance on trade is an empirical question.

\section{Data and estimation method}

\subsection{Trade data}

As the dependent variable we use bilateral exports between two countries measured in thousands of US dollars. For this variable we used the database complied by Feenstra et al. (2005), which is based on trade data from the United Nations. The database covers bilateral

\footnotetext{
${ }^{3}$ Export and FDI can be substitutes in case of horizontal FDI (sales to the local market). Although the bulk of FDI is horizontal in nature, (see, for example, Brakman et al., 2007), vertical FDI has increased due to fragmentation of production. In this case, trade and FDI act as complements. Hence we would expect a negative effect of cultural and institutional distance on both vertical FDI and trade. Therefore, this type of FDI does not lead to a positive substitution effect from FDI to trade. A similar reasoning applies to international outsourcing and resulting trade.
} 
trade between 1962 and 2000. For the purpose of this study only cross-section data is required, so we only used data for the year 2000.

The data are classified according to the Standard International Trade Classification (SITC) revision 2 at the 4-digit level. The SITC is a system that provides codes for product types. At the 4-digit level there can be a maximum of 10,000 different codes. In practice there are less than 10,000 because not all numbers are being used.

To compare our results with Rauch (1999) we use the same set of countries as he did, as far as possible. The 55 remaining countries are listed in the Appendix. It is possible that the value of a trade flow reported by the exporter differs from the trade flow reported by the importer. When this is the case the value reported by the importer is used because this data is generally more reliable (Feenstra et al., 2005). When there is no record from the importing country available we use the record from the exporting country.

According to the database, the total amount of trade in 2000 between the 55 countries used in this study was about 5.3 trillion US dollars. The three Rauch groups, viz. differentiated goods $(\mathrm{N})$, reference priced goods $(\mathrm{R})$ and goods that are traded on an organized exchange (W) account for, respectively, 64\%, 16\% and 10\% of total trade. These shares do not add up to $100 \%$, because not all 4-digit SITC codes are attributed to one of the three categories. Table 1 shows information on total trade flows, classified according to 1-digit SITC codes and the three Rauch groups. 
Table 1. Shares of differentiated, reference priced goods and goods traded on organized exchanges in 1-digit SITC product groups

\begin{tabular}{|c|c|c|c|c|c|c|c|c|c|c|}
\hline \multirow{2}{*}{$\begin{array}{l}\text { Product group } \\
\text { 0: food and live animals }\end{array}$} & \multicolumn{2}{|c|}{$\begin{array}{l}\text { Trade value } \\
\text { billions US\$ }\end{array}$} & \multicolumn{2}{|c|}{$\begin{array}{l}\text { Share of } \mathrm{N} \\
\text { in } \%\end{array}$} & \multicolumn{2}{|c|}{$\begin{array}{l}\text { Share of } \mathrm{R} \\
\text { in } \%\end{array}$} & \multicolumn{2}{|c|}{$\begin{array}{c}\text { Share of W } \\
\text { in } \%\end{array}$} & \multicolumn{2}{|c|}{$\begin{array}{l}\text { Share of not } \\
\text { classified } \%\end{array}$} \\
\hline & 282 & {$[5]$} & 19 & [2] & 46 & [15] & 34 & {$[17]$} & 1 & [1] \\
\hline 1: beverages and tobacco & 46 & {$[1]$} & 10 & [0] & 79 & [4] & 9 & {$[1]$} & 2 & [0] \\
\hline $\begin{array}{l}\text { 2: crude materials, } \\
\text { inedible, except fuels }\end{array}$ & 178 & [3] & 31 & [2] & 48 & [10] & 21 & {$[7]$} & 0 & {$[0]$} \\
\hline $\begin{array}{l}\text { 3: mineral fuels, lubricants } \\
\text { and related materials }\end{array}$ & 430 & [8] & 1 & [0] & 12 & [6] & 78 & {$[60]$} & 9 & [7] \\
\hline $\begin{array}{l}\text { 4: animal and vegetable } \\
\text { oils, fats and waxes }\end{array}$ & 14 & {$[0]$} & 9 & [0] & 10 & [0] & 63 & {$[2]$} & 18 & {$[0]$} \\
\hline $\begin{array}{l}\text { 5: chemicals and related } \\
\text { products }\end{array}$ & 513 & [10] & 46 & [7] & 53 & [32] & 1 & [1] & 0 & {$[0]$} \\
\hline 6: manufactured goods & 721 & [14] & 45 & [10] & 39 & [33] & 9 & [12] & 7 & [10] \\
\hline $\begin{array}{l}\text { 7: machinery and transport } \\
\text { equipment }\end{array}$ & 2310 & [44] & 85 & [59] & 0 & [0] & 0 & [0] & 15 & [66] \\
\hline $\begin{array}{l}\text { 8: miscellaneous } \\
\text { manufactured articles }\end{array}$ & 697 & [13] & 95 & [20] & 0 & [0] & 0 & [0] & 5 & [7] \\
\hline $\begin{array}{l}\text { 9: commodities and } \\
\text { transactions n.e.s. }\end{array}$ & 101 & [2] & 50 & [2] & 0 & [0] & 5 & [1] & 45 & [9] \\
\hline Total & 5292 & [100] & 64 & [100] & 16 & 100] & 10 & [100] & 10 & 100] \\
\hline
\end{tabular}

Notes: $\mathrm{N}=$ Differentiated goods, $\mathrm{R}=$ Reference priced goods and $\mathrm{W}=$ goods traded on an organized exchange. Numbers between square brackets show the importance (in percentages) of each 1-digit SITC group for the whole category, whereas the main figures in each column show the total value of trade for each 4-digit SITCgroup and its subdivision in \%. For example, when we look at SITC-group 0, total trade value is 282 billion, which can be subdivided in $19 \% \mathrm{~N}, 46 \% \mathrm{R}, 34 \% \mathrm{~W}$ and $1 \%$ not classified. Trade in the SITC-group 0 accounts for $5 \%$ of total trade, $2 \%$ of N, $15 \%$ of $\mathrm{R}, 17 \%$ of $\mathrm{W}$, and $1 \%$ of not classified.

The Table reveals that SITC group 7 (machinery and transport equipment) is by far the most important SITC group in terms of trade: $44 \%$ of total trade value is in this category. As the whole group falls under the category of heterogeneous products, it even accounts for almost $60 \%$ of total trade in heterogeneous products. Second largest are the manufactured goods (SITC 6), which are more or less equally divided over the heterogeneous and reference priced goods. Manufactured goods together with chemicals (SITC 5) are the most important reference priced goods and cover about two thirds of trade in that category. Goods traded on world exchange are predominantly mineral fuels (SITC 3, 60\%). 


\subsection{Multidimensional distance}

A main contribution of our analysis is the introduction of multiple dimensions of distance, with an explicit distinction between cultural and institutional differences. We use these distance measures in addition to the links variable used by Rauch (1999), which indicates whether or not two countries share a language or have colonial ties. It is constructed as a dummy variable that equals 1 if both countries share a common language or one country has ever colonized the other country. The data on languages and colonial ties have been compiled by CEPII.

Regarding the role of cultural differences, previous research has typically used measures of cultural (un)familiarity, such as dummy variables indicating whether the trading partners share a common language, religion, and colonial past (e.g., Srivastava and Green, 1986; Anderson and Marcouiller, 2002; De Groot et al., 2004). We use the same measure for cultural (dis)similarity as Linders et al. (2005), which is based on the well-established cultural framework of Hofstede (1980; 2001). In our construction we use his four original cultural dimensions: (i) power distance, (ii) uncertainly avoidance, (iii) individualism and (iv) masculinity. ${ }^{4}$ Our measure captures the extent of differences in norms and values between countries, and hence allows us to go beyond more traditional measures of cultural familiarity.

We also use a refined measure of institutional distance. Previous research has measured the institutional dissimilarity between trading partners through a dummy variable indicating whether the partners had comparable governance quality levels (De Groot et al., 2004). We use a cardinal measure that captures the extent to which these quality levels differ. Our measure of institutional distance is based on Kaufmann et al. (2003). They constructed six indicators for the quality of institutions. These indicators are (i) voice and accountability, (ii) political stability, (iii) government effectiveness, (iv) regulatory quality, (v) rule of law and (vi) control of corruption.

Bilateral cultural and institutional distance are both measured using the Kogut-Singh (1988) index. This index provides a single comparative measure based on the differences between two countries in multiple dimensions. It is constructed by taking a weighted average of the squared difference in each dimension. With $D$ dimensions this yields:

$$
K S_{i j}=\frac{1}{D} \sum_{d=1}^{D} \frac{\left(S_{d i}-S_{d j}\right)^{2}}{V_{d}},
$$

\footnotetext{
${ }^{4}$ Later Hofstede added long-term orientation as a fifth dimension, but it is available for only a few countries and therefore not included here.
} 
where $K S_{i j}$ is the (Kogut-Singh) distance variable, $S_{d i}$ is the value of dimension $d$ for country $i$, $S_{d j}$ is the value of dimension $d$ for country $j$, and $V_{d}$ is the sample variance in dimension $d$.

A description of data and data sources concerning the other explanatory variables included in our gravity model, such as GDP, GDP per capita and physical distance, is provided in the Appendix.

\subsection{Estimation method}

Although most countries do trade with each other, they do not necessarily trade in every product category. Given our focus on trade at a disaggregate level, this implies that there are a number of zero-trade-flows in our sample. Simply neglecting the zero flows may seriously bias the results of an OLS regression analysis based on a loglinear transformation of the gravity equation. The 55 countries from our sample have 2752 bilateral trade flows, out of a possible 2916. When only the products traded on organised exchanges are considered, only 2265 country pairs with a positive trade flow remain. This amount of zero flows can get much larger as more specific product groups are considered. At a 1-digit SITC level as much as $60 \%$ (SITC 4) of the country pairs do not trade.

In order to address the potential bias caused by the neglect of zero-flows, we estimate a sample selection model to take into account zero-valued bilateral trade flows in the sample. This model, also known as the Tobit II model (Verbeek, 2004), specifies a probit selection equation for the decision whether or not to trade, in addition to the standard log-linear gravity equation that models the volume of bilateral trade. ${ }^{5}$ Economic reasoning suggests that the selection equation should at least contain those explanatory variables also included in the gravity equation.

The sample selection model can be estimated using two different approaches. First, the parameters in both parts of the model can be jointly estimated using maximum likelihood. Alternatively, the model can be estimated in two steps (Heckman, 1979). The first step estimates a probit selection equation using maximum likelihood. From the parameter estimates in the selection equation, we can compute the inverse Mill's ratio for each country

\footnotetext{
5 Alternatively, some authors estimate the gravity model using Poisson regression (e.g., Santos-Silva and Tenreyro, 2006). However, Poisson regression pertains mostly to a context in which data are counts, rather than (essentially continuous) monetary values. Furthermore, Poisson estimation does not work well if outcomes are (very) large. So far, the discussion on the appropriateness and value-added of Poisson methods in this context remains an open issue in the literature. See, for example, Martinez-Zarzoso et al. (2007) for a critique of Poisson regression in the context of modelling bilateral trade patterns. Therefore, we prefer to pertain to the conventional log-linear specification and concomitant estimation methods, using a selection model to explicitly acknowledge the special nature of zero flows.
} 
pair, denoted $\lambda_{i j}$ (also known as Heckman's lambda). If we include Heckman's lambda as an additional regressor in the second-stage estimation of the gravity equation, the remaining residual is uncorrelated with the selection outcome, and the gravity model parameters can be estimated consistently with OLS. The parameter estimated for Heckman's lambda in the second-stage regression captures initial selection bias in the residual of the gravity equation.

In our estimations, we use the first approach, based on full maximum likelihood estimation of the parameters in the sample selection model. There are two reasons for this, as described by Verbeek (2004). First, the two-step estimator is generally inefficient and the OLS regression provides incorrect standard errors, because the remaining residual is heteroskedastic, and $\lambda_{i j}$ is not directly observed but estimated from the first-stage regression estimates. Second, the two-step approach will not work very well if $\lambda_{i j}$ varies little across observations and is close to being linear in the regressors. This is related to potential identification problems that occur if the explanatory variables in the selection and regression equation are identical. In this case, the two-stage sample selection model is only identified because $\lambda_{i j}$ is a non-linear function of the regressors whereas these regressors enter (log-) linearly in the gravity equation (see Vella, 1998). The full maximum likelihood estimation provides an integrated approach to estimate the parameters in both the selection and regression equations, instead of relying on the second-stage estimation of an extended (log-) linear gravity equation using OLS. To conform to earlier empirical applications in trade modelling, we have included an additional regressor in the selection equation nevertheless.

On the matter of identification, Verbeek (2004, p. 232) notes that: "the inclusion of [regressor] variables in [the selection equation] in addition to those [already in the regression model] can be important for identification in the second step", but adds: "often there are no natural candidates and any choice is easily criticized". We follow Helpman et al. (2007) in using an indicator for common religion as an additional regressor in the selection equation for this purpose. However, if this regressor is incorrectly omitted from the gravity equation, the estimation results may suffer from omitted variables bias and lead to spurious conclusions on the existence of sample selection bias (Verbeek, 2004). To perform some sensitivity analysis on the implied exclusion restriction with respect to the religion variable, we also estimate a sample selection model including the religion indicator in the gravity equation as well. 


\section{Results}

This section discusses the results of our analyses. Section 5.1 updates the analysis by Rauch (1999) by (i) considering a more recent time period and (ii) applying recently developed estimation techniques. Section 5.2 then continues by elaborating on the importance of other intangible barriers to trade. In Section 5.3, we look at more disaggregate product groups.

\subsection{An update of Rauch (1999)}

The results in Table 2 are obtained using a specification similar to the specification used by Rauch (1999). Our analysis is based on data for 2000, whereas Rauch used data for 1990. A minor difference in specification is that we include a generic dummy for common trade bloc membership while Rauch (1999) included a dummy for common membership of the EEC and for common membership of the EFTA. Table 2 shows the results for the total amount of trade, the trade in heterogeneous goods $(\mathrm{N})$, trade in referenced priced goods $(\mathrm{R})$ and trade in goods which are traded on organised exchanges (W). The coefficients are estimated using Ordinary Least Squares (OLS) with a balanced sample. Only the country pairs that have a positive amount in all four groups are included in the analysis. From the 2970 possible country pairs, $2142(72 \%)$ have a positive amount of trade in each of these categories.

The results in Table 2 are comparable with those obtained by Rauch (1999) for the year 1990, which is the most recent year he used. The explained variation of trade is of the same order of magnitude, ranging from around 0.4 for homogeneous goods to around 0.7 for heterogeneous goods and aggregate trade. Also the signs and sizes of the estimated coefficients are comparable. We find a similar pattern for the GDP and per capita GDP coefficients, which tend to decrease as one moves from trade in heterogeneous goods towards trade in goods that are traded on organized exchanges. However, we do not find a clear pattern for the effect of links. The size of the adjacency effect is clearly increasing as the products become more homogeneous. For goods traded on organized exchanges the adjacency effect is particularly high. 
Table 2. An update of Rauch's analysis - I

\begin{tabular}{|c|c|c|c|c|}
\hline Dependent variable: & $\ln ($ total trade value $)$ & $\ln ($ trade value $\mathrm{N})$ & $\ln ($ trade value $\mathrm{R})$ & $\ln ($ trade value $\mathrm{W})$ \\
\hline & Total & Differentiated & Reference priced & Organized exchange \\
\hline Specification & Rauch & Rauch & Rauch & Rauch \\
\hline \multirow[t]{2}{*}{$\ln ($ GDP product $)$} & $0.83^{* * *}$ & $0.96^{* * *}$ & $0.81^{* * * *}$ & $0.74^{* * *}$ \\
\hline & $(0.01)$ & $(0.02)$ & $(0.02)$ & $(0.02)$ \\
\hline \multirow[t]{2}{*}{$\ln ($ per capita GDP product) } & $0.57^{* * * *}$ & $0.74^{* * * *}$ & $0.51^{* * * *}$ & $0.16^{* * *}$ \\
\hline & $(0.02)$ & $(0.03)$ & $(0.03)$ & $(0.04)$ \\
\hline \multirow[t]{2}{*}{$\ln ($ distance $)$} & $-0.66^{* * *}$ & $-0.81^{* * *}$ & $-0.67^{* * *}$ & $-0.66^{* * *}$ \\
\hline & $(0.03)$ & $(0.04)$ & $(0.03)$ & $(0.05)$ \\
\hline \multirow[t]{2}{*}{ Adjacency } & $0.22^{* *}$ & -0.03 & $0.33^{* * * *}$ & $0.75^{* * *}$ \\
\hline & $(0.11)$ & $(0.15)$ & $(0.10)$ & $(0.17)$ \\
\hline \multirow[t]{2}{*}{ Links } & $0.56^{* * *}$ & $0.66^{* * *}$ & $0.60^{* * * *}$ & $0.61^{* * * *}$ \\
\hline & $(0.06)$ & $(0.08)$ & $(0.08)$ & $(0.10)$ \\
\hline \multirow{2}{*}{$\begin{array}{l}\text { Common trade bloc } \\
\text { membership }\end{array}$} & $0.68^{* * *}$ & $0.78^{* * *}$ & $0.89^{* * *}$ & $0.82^{* * *}$ \\
\hline & $(0.05)$ & $(0.07)$ & $(0.07)$ & $(0.10)$ \\
\hline Method & OLS & OLS & OLS & OLS \\
\hline Country dummies & No & No & no & No \\
\hline $\mathrm{R}^{2}$-Adjusted & 0.75 & 0.69 & 0.67 & 0.40 \\
\hline Total observations & 2142 & 2142 & 2142 & 2142 \\
\hline
\end{tabular}

In Table 3 we expand the previous analysis by adding country-specific dummies to control for country-specific multilateral trade resistance, consistent with Anderson and Van Wincoop (2003). The effects of GDP and distance tend to increase whereas the effect of a common trade bloc membership decreases. The effect of links now also has a clear pattern, being high for heterogeneous goods and relatively small for goods traded on organized exchanges. It is also interesting to see that the effect of sharing a common border becomes much smaller for referenced price goods and for goods traded on organized exchanges. At the same time, distance decay becomes more pronounced. The estimators for distance and for the adjacency dummy are closely related to each other, as the positive result for a common border is partly caused by mismeasurement of the distance (Head and Mayer, 2007). This may suggest that the distance effect can be estimated more accurately, or that the functional form works better when including country dummies. 
Table 3. An update of Rauch's analysis - II (including country dummies)

\begin{tabular}{|c|c|c|c|c|}
\hline Dependent variable: & $\ln ($ total trade value $)$ & $\ln ($ trade value $\mathrm{N})$ & Ln(trade value $\mathrm{R})$ & $\ln ($ trade value $\mathrm{W})$ \\
\hline & Total & Differentiated & Reference priced & Organized exchange \\
\hline Specification & $\begin{array}{c}\text { Rauch + } \\
\text { country dummies }\end{array}$ & $\begin{array}{c}\text { Rauch }+ \\
\text { country dummies } \\
\end{array}$ & $\begin{array}{c}\text { Rauch }+ \\
\text { country dummies }\end{array}$ & $\begin{array}{c}\text { Rauch }+ \\
\text { country dummies } \\
\end{array}$ \\
\hline \multirow[t]{2}{*}{$\ln ($ GDP product $)$} & $0.79^{* * *}$ & $0.90^{* * * *}$ & $0.85^{* * *}$ & $0.73^{* * *}$ \\
\hline & $(0.03)$ & $(0.04)$ & $(0.03)$ & $(0.05)$ \\
\hline \multirow[t]{2}{*}{$\ln ($ per capita GDP product) } & $1.04^{* * * *}$ & $1.22^{* * * *}$ & $0.69^{\text {**** }}$ & $0.68^{* * * *}$ \\
\hline & $(0.05)$ & $(0.06)$ & $(0.06)$ & $(0.09)$ \\
\hline \multirow[t]{2}{*}{$\ln ($ distance $)$} & $-0.72^{* * *}$ & $-0.78^{* * *}$ & $-0.86^{* * *}$ & $-0.95^{* * *}$ \\
\hline & $(0.04)$ & $(0.05)$ & $(0.05)$ & $(0.07)$ \\
\hline \multirow[t]{2}{*}{ Adjacency } & $0.23^{*}$ & 0.17 & 0.14 & $0.37^{*}$ \\
\hline & $(0.13)$ & $(0.16)$ & $(0.13)$ & $(0.20)$ \\
\hline \multirow[t]{2}{*}{ Links } & $0.53^{* * *}$ & $0.66^{* * *}$ & $0.60^{* * * *}$ & $0.36^{* * *}$ \\
\hline & $(0.07)$ & $(0.08)$ & $(0.08)$ & $(0.12)$ \\
\hline \multirow{2}{*}{$\begin{array}{l}\text { Common trade bloc } \\
\text { membership }\end{array}$} & $0.60^{* * *}$ & $0.68^{* * *}$ & $0.64^{* * * *}$ & $0.69^{* * * *}$ \\
\hline & $(0.06)$ & $(0.08)$ & $(0.08)$ & $(0.12)$ \\
\hline Method & OLS & OLS & OLS & OLS \\
\hline Country dummies & 54 & 54 & 54 & 54 \\
\hline $\mathrm{R}^{2}$-Adjusted & 0.82 & 0.78 & 0.76 & 0.49 \\
\hline Total observations & 2142 & 2142 & 2142 & 2142 \\
\hline
\end{tabular}

We now apply the sample selection model instead of OLS. The results are depicted in Table 4. The use of the selection model only marginally changes the results. 
Table 4. An update of Rauch's analysis - III (Heckman selection model)

\begin{tabular}{|c|c|c|c|c|}
\hline Dependent variable: & Ln(total trade value) & $\ln ($ trade value $\mathrm{N})$ & $\ln ($ trade value $\mathrm{R})$ & $\ln ($ trade value $\mathrm{W})$ \\
\hline & Total & Differentiated & Reference priced & Organized exchange \\
\hline Specification & $\begin{array}{c}\text { Rauch }+ \\
\text { country dummies } \\
\end{array}$ & $\begin{array}{c}\text { Rauch }+ \\
\text { country dummies } \\
\end{array}$ & $\begin{array}{c}\text { Rauch }+ \\
\text { Country dummies } \\
\end{array}$ & $\begin{array}{c}\text { Rauch }+ \\
\text { country dummies }\end{array}$ \\
\hline $\ln ($ GDP product $)$ & $\begin{array}{l}0.82^{* * *} \\
(0.03)\end{array}$ & $\begin{array}{l}0.88^{* * *} \\
(0.04)\end{array}$ & $\begin{array}{l}0.85^{* * *} \\
(0.03)\end{array}$ & $\begin{array}{l}0.72^{* * *} \\
(0.06)\end{array}$ \\
\hline $\ln$ (per capita GDP product) & $\begin{array}{l}1.09^{* * *} \\
(0.06)\end{array}$ & $\begin{array}{l}1.26^{* * *} \\
(0.07)\end{array}$ & $\begin{array}{l}0.67^{* * * *} \\
(0.06)\end{array}$ & $\begin{array}{l}0.65^{* * *} \\
(0.10)\end{array}$ \\
\hline $\ln ($ distance $)$ & $\begin{array}{c}-0.85^{* * *} \\
(0.04)\end{array}$ & $\begin{array}{c}-0.81^{* * * *} \\
(0.05)\end{array}$ & $\begin{array}{c}-0.92^{* * * *} \\
(0.05)\end{array}$ & $\begin{array}{c}-0.95^{* * *} \\
(0.08)\end{array}$ \\
\hline Adjacency & $\begin{array}{c}0.08 \\
(0.14)\end{array}$ & $\begin{array}{c}0.12 \\
(0.16)\end{array}$ & $\begin{array}{c}0.06 \\
(0.15)\end{array}$ & $\begin{array}{c}0.39^{*} \\
(0.23)\end{array}$ \\
\hline Links & $\begin{array}{l}0.61^{* * *} \\
(0.07)\end{array}$ & $\begin{array}{l}0.69^{* * *} \\
(0.08)\end{array}$ & $\begin{array}{l}0.63^{* * *} \\
(0.08)\end{array}$ & $\begin{array}{l}0.31^{* *} \\
(0.12)\end{array}$ \\
\hline $\begin{array}{l}\text { Common trade bloc } \\
\text { membership }\end{array}$ & $\begin{array}{l}0.56^{* * *} \\
(0.08) \\
\end{array}$ & $\begin{array}{l}0.63^{* * *} \\
(0.09) \\
\end{array}$ & $\begin{array}{l}0.65^{* * *} \\
(0.08)\end{array}$ & $\begin{array}{l}0.71^{* * * *} \\
(0.13)\end{array}$ \\
\hline Method & Heckman & Heckman & Heckman & Heckman \\
\hline Country dummies & 54 & 54 & 54 & 54 \\
\hline Uncensored obs. & 2752 & 2627 & 2586 & 2265 \\
\hline Censored obs. & 164 & 289 & 330 & 651 \\
\hline
\end{tabular}

There is a clear pattern present for five variables: GDP, GDP per capita, distance, links and common trade bloc membership. The GDP coefficient for differentiated goods (0.88) is higher than for referenced priced goods $(0.85)$ and for goods traded at organised exchanges (0.72). A similar pattern was found by Rauch (1999). The pattern for the GDP per capita is even more pronounced, ranging from 1.26 for heterogeneous goods to 0.65 for homogeneous goods. This suggests that heterogeneous goods are income elastic while homogeneous goods are income inelastic. Since we use the product of GDP per capita of the exporter and the importer, it is also possible that high-income countries export relatively more heterogeneous goods than homogeneous goods. This could be caused by comparative advantages of highincome countries for heterogeneous goods.

For the links variable we also find the same pattern as Rauch (1999). For all three product categories trade will be higher when the trading partners have colonial links or share a common language. The size of this effect increases with the extent of differentiation of the products. This is one of the main conclusions of Rauch (1999) and is consistent with his network/search theory.

According to the network/search view, distance would reduce trade in heterogeneous goods more than it would reduce trade in homogeneous goods. The results of Rauch (1999) 
confirmed this hypothesis and are consistent with those found in Table 2. However, when we add country dummies (Table 3 ) and apply the Heckman selection model (Table 4), the results suggest the opposite effect. Physical distance reduces trade more for homogeneous goods. A possible explanation for this is that for homogeneous goods, exactly the same good can be imported from many countries. Because of the nature of these goods, it does not matter where the goods come from. Heterogeneous goods are probably produced in fewer places. Moreover, if similar but differentiated goods are produced in multiple places, they may vary in quality, giving more reason to trade the goods over a larger distance. Second, when goods are traded on organised exchanges, intangible trade costs probably play a smaller role. There is less need for negotiation over the properties of the product or the price. Therefore, the importance of tangible costs like transportation costs, relative to the importance of intangible transaction costs, is likely to be higher for homogeneous goods than it is for heterogeneous goods. Though this may either increase or decrease distance decay, depending on the relative importance of transportation costs and intangible transaction costs in explaining the marginal effect of distance on trade.

Tariffs are also a form of tangible trade costs. The idea behind the common trade bloc variable is that it acts as a proxy for tariffs and other forms of trade protection, which should be lower when both countries are a member of the same trade bloc. Common trade bloc membership can therefore be expected to be more important for homogeneous goods. This is confirmed by the pattern for the trade bloc coefficient. This coefficient is, like the distance coefficient, higher for the group of products that is traded on organised exchanges $(0.71)$ than for referenced priced goods (0.65) and for differentiated goods (0.63). An alternative explanation is that trade protection is more severe for goods traded on organised exchanges.

\subsection{The impact of cultural and institutional distance}

We now turn to the impact of cultural and institutional dissimilarities. Table 5 extends the specification with two variables reflecting these intangible barriers to trade. The coefficients for the other variables, that were already included in Table 4, are hardly affected by the inclusion of institutional and cultural distance, so we will focus on the results for institutional and cultural distance. Based on the discussion in Section 3, the expected sign of the effect of cultural and institutional distance is ambiguous. On the one hand a negative effect on bilateral trade could be expected, because trade costs increase with cultural and institutional distance. Then the negative effect is expected to be more pronounced for goods that are more differentiated, because higher asset-specific investments in trade relations imply a greater risk 
of exposure to differences in culture and institutional quality. However, on the other hand, high cultural and institutional differences lower the attractiveness of serving foreign markets with FDI and may lead to substitution by trade flows. The total effect of cultural and institutional distance on trade could then even be positive. The empirical analysis is needed to assess the relative importance of both opposite powers.

Table 5. The role of cultural and institutional distance

\begin{tabular}{|c|c|c|c|c|}
\hline Dependent variable: & $\ln ($ total trade value $)$ & $\ln ($ trade value $\mathrm{N})$ & $\ln ($ trade value $\mathrm{R})$ & $\ln ($ trade value $\mathrm{W})$ \\
\hline & Total & Differentiated & Reference priced & Organized exchange \\
\hline Specification & $\begin{array}{c}\text { Rauch }+ \\
\text { country dummies }\end{array}$ & $\begin{array}{c}\text { Rauch }+ \\
\text { country dummies }\end{array}$ & $\begin{array}{c}\text { Rauch }+ \\
\text { country dummies }\end{array}$ & $\begin{array}{c}\text { Rauch }+ \\
\text { country dummies }\end{array}$ \\
\hline \multirow[t]{2}{*}{ Ln(GDP product) } & $0.83^{* * *}$ & $0.88^{* * *}$ & $0.85^{* * *}$ & $0.71^{* * *}$ \\
\hline & $(0.03)$ & $(0.04)$ & $(0.03)$ & $(0.06)$ \\
\hline \multirow[t]{2}{*}{ Ln(per capita GDP product) } & $1.08^{* * * *}$ & $1.24^{* * *}$ & $0.71^{* * *}$ & $0.67^{* * * *}$ \\
\hline & $(0.06)$ & $(0.06)$ & $(0.06)$ & $(0.10)$ \\
\hline \multirow[t]{2}{*}{ Ln(distance) } & $-0.86^{* * *}$ & $-0.82^{* * *}$ & $-0.91^{* * *}$ & $-0.93^{* * * *}$ \\
\hline & $(0.05)$ & $(0.05)$ & $(0.05)$ & $(0.08)$ \\
\hline \multirow[t]{2}{*}{ Adjacency } & 0.09 & 0.13 & 0.00 & $0.39^{*}$ \\
\hline & $(0.14)$ & $(0.16)$ & $(0.15)$ & $(0.23)$ \\
\hline \multirow[t]{2}{*}{ Links } & $0.62^{* * *}$ & $0.71^{* * *}$ & $0.62^{* * *}$ & $0.25^{*}$ \\
\hline & $(0.07)$ & $(0.08)$ & $(0.08)$ & $(0.13)$ \\
\hline \multirow{2}{*}{$\begin{array}{l}\text { Common trade bloc } \\
\text { membership }\end{array}$} & $0.57^{* * *}$ & $0.62^{* * * *}$ & $0.60^{* * *}$ & $0.78^{* * * *}$ \\
\hline & $(0.08)$ & $(0.09)$ & $(0.08)$ & $(0.13)$ \\
\hline \multirow[t]{2}{*}{ Cultural distance } & 0.02 & 0.04 & -0.02 & $-0.11^{* * *}$ \\
\hline & $(0.02)$ & $(0.02)$ & $(0.02)$ & $(0.04)$ \\
\hline \multirow[t]{2}{*}{ Institutional distance } & 0.01 & -0.01 & $-0.06^{* * *}$ & $0.10^{* * * *}$ \\
\hline & $(0.02)$ & $(0.02)$ & $(0.02)$ & $(0.03)$ \\
\hline Method & Heckman & Heckman & Heckman & Heckman \\
\hline Country dummies & 54 & 54 & 54 & 54 \\
\hline Uncensored obs. & 2752 & 2627 & 2586 & 2265 \\
\hline Censored obs. & 164 & 289 & 330 & 651 \\
\hline
\end{tabular}

The empirical findings reported in Table 5 provide support for the latter explanation. Cultural and institutional distance are statistically insignificant determinants for total trade and trade in group $\mathrm{N}$ (which accounts for the bulk of the total trade). Furthermore, the coefficient of cultural distance is becoming more negative as the product groups become more homogeneous. This result contradicts the expectation from the first explanation that cultural distance is especially important for heterogeneous goods and that cultural distance is less important for goods that are traded on organised exchanges, because trade occurs at arms' length. This latter group is the only product group where cultural distance has a statistically 
significant negative effect on trade. For institutional distance the results do not confirm the traditional hypothesis either. This variable is insignificant for aggregate bilateral trade and trade in heterogeneous goods, significant and negative for reference priced goods, and significant and positive for goods traded on organised exchanges.

Substitution between trade and FDI provides a possible explanation for the pattern of cultural distance that we find. The findings for the three product groups could be interpreted, according to this line of thought, as follows: the substitution effect from FDI to trade appears to increase as products are less homogeneous. This could actually reflect that the substitutability of different suppliers in trade is smaller for more differentiated goods, implying that the bilateral relation changes form in the face of higher cultural and institutional distance. For homogeneous goods, on the other hand, importers may rely on exporters that are relatively close in terms of culture and institutions. Substituting away in both trade and FDI relations from suppliers that are more distant is easier. This line of reasoning is consistent with the findings for the effect of cultural distance on trade across product groups. A qualification on this explanation should be that, ceteris paribus, we expect FDI to be a more attractive option for differentiated types of goods. Because trade costs related to search and insecurity are expected to be higher for more differentiated goods, FDI becomes relatively more attractive. Because these trade costs increase more with distance and other barriers, while FDI costs increase similarly for all types of goods, we would expect a smaller percentage substitution from FDI to trade for differentiated goods.

The pattern for institutional distance does not correspond to the hierarchy following from the FDI-trade substitution, however. It could be expected that institutional distance does not have a strong effect on trade in group $\mathrm{W}$, because country-specific institutions are not that relevant for goods that are traded on organized exchanges. Organized exchanges form an institutional framework in itself. The effect, however, is actually significantly positive, suggesting a high substitution from FDI to trade. A possible explanation for this is that homogeneous goods are generally produced by countries with relatively low institutional quality and exported to countries with relatively high institutional quality. ${ }^{6}$

\footnotetext{
${ }^{6}$ We have also included institutional quality as a separate explanatory variable (although it is strongly correlated with GDP per capita). Institutional quality especially stimulates trade for the differentiated product group, which accounts for the bulk of the total trade. For reference priced goods and goods that are traded on organized exchanges, the institutional quality does not significantly increase trade. This confirms the prediction of the insecurity view on trade costs that the effectiveness of the formal institutional framework of a country in enforcing property rights matters particularly for differentiated products and not so much for homogeneous goods. In specifications that include country dummies, the level of institutional quality is controlled for by the dummy parameters.
} 


\subsection{More detailed product groups}

The above results clearly reveal that the effects of tangible and intangible barriers to trade vary according to the type of product that is being traded. As a final extension to the analysis we now look at even more disaggregate product groups. We consider the ten 1-digit product categories distinguished in the SITC classification. The results are presented in Table 6.

A result that stands out is the substantial heterogeneity in the estimated coefficients for the different product groups. The GDP variable, for example, ranges from 0.51 to 0.90 . The GDP per capita variable has an even larger range, between 0.47 and 1.54. Striking is also the variation in the impact of physical distance ranging from -0.56 for beverages and tobacco to -1.42 for mineral fuels, lubricants and related materials. The markets for the latter goods can thus be characterized as highly localized.

There are three product groups (SITC 0,2 and 4) that have a relatively low coefficient for GDP per capita and a relatively high coefficient for the trade bloc variable. As such, the results for these three categories strongly resemble those of the goods traded on organized exchanges (see Table 5). As shown in Table 1, these three product groups also contain relatively high shares of homogeneous products.

An interesting result is that cultural distance has a negative coefficient for all 1-digit product groups, except for machinery and transport equipment (SITC 7), for which it is significantly positive. This product group has a particularly large share in total trade. Table 1 shows that machinery and transport equipment account for over $40 \%$ of the total trade between the countries in our sample. This implies that this product group is probably responsible for the insignificant effect which was found for total trade and trade in heterogeneous goods. For the other product groups, culture does seem to impose a barrier to trade. ${ }^{7}$ When ignoring all trade in SITC 7 , cultural distance has a coefficient of -0.04 , with a $p$-value of 0.1 .

\footnotetext{
${ }^{7}$ The effect of cultural distance on food and live animals (SITC 0) is not particularly large, even though this product group is generally considered as a culture-specific product. This could be explained by a preference for variety. Since some food-related products are only produced in certain countries, they can only be imported from countries with a different culture. This effect would reduce the negative effect of cultural distance on trade.
} 
Table 6. Results for SITC 1 product groups

\begin{tabular}{|c|c|c|c|c|c|}
\hline $\begin{array}{l}\text { Dependent } \\
\text { variable: }\end{array}$ & $\begin{array}{l}\ln (0: \text { food and } \\
\text { live animals })\end{array}$ & $\begin{array}{l}\ln (1: \text { beverages } \\
\text { and tobacco })\end{array}$ & $\begin{array}{c}\ln (2: \text { crude } \\
\text { materials, } \\
\text { inedible, except } \\
\text { fuels })\end{array}$ & $\begin{array}{c}\ln (3: \text { mineral } \\
\text { fuels, lubricants } \\
\text { and related } \\
\text { materials })\end{array}$ & $\begin{array}{l}\ln (4: \text { animal and } \\
\text { vegetable oils, fats } \\
\text { and waxes })\end{array}$ \\
\hline Specification & $\begin{array}{c}\text { Rauch }+ \\
\text { country dummies }\end{array}$ & $\begin{array}{c}\text { Rauch }+ \\
\text { country dummies }\end{array}$ & $\begin{array}{c}\text { Rauch }+ \\
\text { country dummies }\end{array}$ & $\begin{array}{c}\text { Rauch }+ \\
\text { country dummies }\end{array}$ & $\begin{array}{c}\text { Rauch }+ \\
\text { country dummies } \\
\end{array}$ \\
\hline $\ln ($ GDP product $)$ & $\begin{array}{l}0.82^{* * *} \\
(0.05)\end{array}$ & $\begin{array}{l}0.53^{* * *} \\
(0.05)\end{array}$ & $\begin{array}{l}0.90^{* * *} \\
(0.04)\end{array}$ & $\begin{array}{l}0.51^{* * *} \\
(0.09)\end{array}$ & $\begin{array}{l}0.80^{* * * *} \\
(0.08)\end{array}$ \\
\hline $\begin{array}{l}\ln \text { (per capita GDP } \\
\text { product) }\end{array}$ & $\begin{array}{l}0.67^{* * *} \\
(0.08)\end{array}$ & $\begin{array}{l}1.14^{* * * *} \\
(0.11)\end{array}$ & $\begin{array}{l}0.47^{* * * *} \\
(0.08)\end{array}$ & $\begin{array}{l}0.77^{* * * *} \\
(0.15)\end{array}$ & $\begin{array}{l}0.54^{* * * *} \\
(0.14)\end{array}$ \\
\hline $\ln ($ distance $)$ & $\begin{array}{c}-0.62^{* * * *} \\
(0.06)\end{array}$ & $\begin{array}{c}-0.56^{* * *} \\
(0.08)\end{array}$ & $\begin{array}{c}-0.66^{* * *} \\
(0.06)\end{array}$ & $\begin{array}{c}-1.42^{* * *} \\
(0.12)\end{array}$ & $\begin{array}{c}-0.64^{* * *} \\
(0.10)\end{array}$ \\
\hline Adjacency & $\begin{array}{c}0.36^{*} \\
(0.19)\end{array}$ & $\begin{array}{l}0.48^{* *} \\
(0.23)\end{array}$ & $\begin{array}{l}0.30^{*} \\
(0.17)\end{array}$ & $\begin{array}{c}0.54^{*} \\
(0.30)\end{array}$ & $\begin{array}{l}0.64^{* * * *} \\
(0.24)\end{array}$ \\
\hline Links & $\begin{array}{l}0.54^{* * * *} \\
(0.10)\end{array}$ & $\begin{array}{l}0.64^{* * *} \\
(0.14)\end{array}$ & $\begin{array}{l}0.44^{* * *} \\
(0.10)\end{array}$ & $\begin{array}{r}-0.22 \\
(0.18)\end{array}$ & $\begin{array}{l}0.45^{* * *} \\
(0.16)\end{array}$ \\
\hline $\begin{array}{l}\text { Common trade } \\
\text { bloc membership }\end{array}$ & $\begin{array}{l}0.99^{* * * *} \\
(0.11)\end{array}$ & $\begin{array}{l}0.54^{* * * *} \\
(0.14)\end{array}$ & $\begin{array}{l}0.70^{* * * *} \\
(0.10)\end{array}$ & $\begin{array}{c}0.37^{*} \\
(0.20)\end{array}$ & $\begin{array}{l}0.79^{* * * *} \\
(0.16)\end{array}$ \\
\hline Cultural distance & $\begin{array}{r}-0.05^{*} \\
(0.03)\end{array}$ & $\begin{array}{c}-0.16^{* * *} \\
(0.04)\end{array}$ & $\begin{array}{r}-0.03 \\
(0.03)\end{array}$ & $\begin{array}{c}-0.16^{* * * *} \\
(0.05)\end{array}$ & $\begin{array}{c}-0.10^{* *} \\
(0.05)\end{array}$ \\
\hline $\begin{array}{l}\text { Institutional } \\
\text { distance }\end{array}$ & $\begin{array}{r}0.06 \\
(0.02) \\
\end{array}$ & $\begin{array}{r}-0.05 \\
(0.04) \\
\end{array}$ & $\begin{array}{c}0.00 \\
(0.02) \\
\end{array}$ & $\begin{array}{c}0.05 \\
(0.05) \\
\end{array}$ & $\begin{array}{c}0.09^{* * *} \\
(0.04)\end{array}$ \\
\hline Method & Heckman & Heckman & Heckman & Heckman & Heckman \\
\hline Country dummies & 54 & 54 & 54 & 54 & 54 \\
\hline Uncensored obs. & 2373 & 1368 & 2250 & 1425 & 1122 \\
\hline Censored obs. & 543 & 1548 & 666 & 1491 & 1794 \\
\hline
\end{tabular}

Notes: Robust standard errors in parentheses. Statistical significance at a $10 \%, 5 \%$ or $1 \%$ level is indicated by ${ }^{*}$, ${ }^{* * *}$ or ${ }^{* * * *}$, respectively. 
Table 6 (continued). Results for SITC 1 product groups

\begin{tabular}{|c|c|c|c|c|c|}
\hline $\begin{array}{l}\text { Dependent } \\
\text { variable: }\end{array}$ & $\begin{array}{l}\ln (5: \text { chemicals } \\
\text { and related } \\
\text { products })\end{array}$ & $\begin{array}{l}\ln (6: \\
\text { manufactured } \\
\text { goods })\end{array}$ & $\begin{array}{l}\ln (7: \text { machinery } \\
\text { and transport } \\
\text { equipment })\end{array}$ & $\begin{array}{c}\ln (8: \\
\text { miscellaneous } \\
\text { manufactured } \\
\text { articles })\end{array}$ & $\begin{array}{c}\ln (9 \text { : commodities } \\
\text { and transactions } \\
\text { n.e.s. })\end{array}$ \\
\hline Specification & $\begin{array}{c}\text { Rauch }+ \\
\text { country dummies }\end{array}$ & $\begin{array}{c}\text { Rauch }+ \\
\text { country dummies }\end{array}$ & $\begin{array}{c}\text { Rauch }+ \\
\text { country dummies }\end{array}$ & $\begin{array}{c}\text { Rauch }+ \\
\text { country dummies }\end{array}$ & $\begin{array}{c}\text { Rauch }+ \\
\text { country dummies }\end{array}$ \\
\hline $\ln ($ GDP product $)$ & $\begin{array}{l}0.81^{* * *} \\
(0.04)\end{array}$ & $\begin{array}{l}0.86^{* * *} \\
(0.03)\end{array}$ & $\begin{array}{l}0.83^{* * *} \\
(0.05)\end{array}$ & $\begin{array}{l}0.90^{* * *} \\
(0.04)\end{array}$ & $\begin{array}{l}0.64^{* * *} \\
(0.07)\end{array}$ \\
\hline $\begin{array}{l}\ln \text { (per capita GDP } \\
\text { product) }\end{array}$ & $\begin{array}{l}0.94^{* * *} \\
(0.07)\end{array}$ & $\begin{array}{l}0.58^{* * * *} \\
(0.06)\end{array}$ & $\begin{array}{l}1.54^{* * *} \\
(0.08)\end{array}$ & $\begin{array}{l}1.31^{* * *} \\
(0.08)\end{array}$ & $\begin{array}{l}1.42^{* * *} \\
(0.13)\end{array}$ \\
\hline $\ln ($ distance $)$ & $\begin{array}{c}-1.02^{* * *} \\
(0.05)\end{array}$ & $\begin{array}{c}-0.93^{* * *} \\
(0.05)\end{array}$ & $\begin{array}{c}-0.70^{* * * *} \\
(0.06)\end{array}$ & $\begin{array}{c}-0.77^{* * * *} \\
(0.06)\end{array}$ & $\begin{array}{c}-0.53^{* * *} \\
(0.11)\end{array}$ \\
\hline Adjacency & $\begin{array}{c}0.02 \\
(0.16)\end{array}$ & $\begin{array}{c}0.15 \\
(0.15)\end{array}$ & $\begin{array}{c}0.32 \\
(0.19)\end{array}$ & $\begin{array}{c}0.18 \\
(0.17)\end{array}$ & $\begin{array}{c}0.49^{*} \\
(0.30)\end{array}$ \\
\hline Links & $\begin{array}{l}0.56^{* * * *} \\
(0.09)\end{array}$ & $\begin{array}{l}0.49^{* * *} \\
(0.08)\end{array}$ & $\begin{array}{l}0.61^{* * *} \\
(0.11)\end{array}$ & $\begin{array}{l}0.83^{* * *} \\
(0.10)\end{array}$ & $\begin{array}{c}0.15 \\
(0.17)\end{array}$ \\
\hline $\begin{array}{l}\text { Common trade } \\
\text { bloc membership }\end{array}$ & $\begin{array}{l}0.40^{* * *} \\
(0.09)\end{array}$ & $\begin{array}{l}0.60^{* * * *} \\
(0.09)\end{array}$ & $\begin{array}{l}0.74^{* * * *} \\
(0.11)\end{array}$ & $\begin{array}{l}0.53^{* * *} \\
(0.10)\end{array}$ & $\begin{array}{l}0.91^{* * * *} \\
(0.17)\end{array}$ \\
\hline Cultural distance & $\begin{array}{r}-0.04 \\
(0.03)\end{array}$ & $\begin{array}{c}-0.06^{* *} \\
(0.02)\end{array}$ & $\begin{array}{c}0.05^{*} \\
(0.03)\end{array}$ & $\begin{array}{r}-0.03 \\
(0.03)\end{array}$ & $\begin{array}{r}-0.09^{*} \\
(0.05)\end{array}$ \\
\hline $\begin{array}{l}\text { Institutional } \\
\text { distance }\end{array}$ & $\begin{array}{c}-0.07^{* * *} \\
(0.02)\end{array}$ & $\begin{array}{c}-0.05^{* * *} \\
(0.02)\end{array}$ & $\begin{array}{r}-0.02 \\
(0.03) \\
\end{array}$ & $\begin{array}{r}-0.04 \\
(0.02) \\
\end{array}$ & $\begin{array}{r}-0.05 \\
(0.05) \\
\end{array}$ \\
\hline Method & Heckman & Heckman & Heckman & Heckman & Heckman \\
\hline Country dummies & 54 & 54 & 54 & 54 & 54 \\
\hline Uncensored obs. & 2321 & 2467 & 2307 & 2223 & 1283 \\
\hline Censored obs. & 595 & 449 & 609 & 693 & 1633 \\
\hline
\end{tabular}

\section{Conclusions}

This paper has focused on the importance of intangible barriers to trade in explaining variation in bilateral trade. As such, the analysis expands in several ways upon the seminal work by Rauch (1999). The new elements as compared to Rauch are that (i) we consider a more recent time period, (ii) we apply more appropriate estimation techniques, (iii) we consider intangible barriers to trade in much more detail, and (iv) we consider more refined product categories.

Our results confirm the network/search theory specified in Rauch (1999) with respect to the effect of linguistic or colonial links. The effect of linguistic or colonial links is larger for more differentiated goods. However, geographical distance shows the opposite pattern when we control for omitted variable bias due to multilateral resistances and account for selection bias due to zero valued trade flows:.it is most important for trade in homogeneous 
goods. This qualifies the importance of distance for search costs relative to more traditional transportation barriers. The analysis of additional cultural and institutional distance variables suggests that these effects are rather different for different product types. Cultural distance exercises a negative influence and institutional distance a positive influence on goods traded on organized exchanges, while both variables are statistically insignificant for trade in differentiated goods. A possible explanation for the positive effect can be found in the tradeoff between FDI and trade. Zooming in on more disaggregated product groups provides further insights on the effect of different dimensions of distance. An interesting result is that for nine out of ten groups cultural distance does have a negative effect on trade.

Although some clear patterns are discernible from the presented evidence, our results also point to a number of opportunities for future research. Particularly promising is to delve deeper into the determination of more homogeneous product groups, extending the classification into three groups proposed by Rauch (1999). An interesting way forward could be to consider trade for more refined product groups and classify them into homogeneous groups based on key characteristics of gravity equations estimated for these groups. Such classifications should acknowledge the multidimensionality of distance. Analyses for more refined product groups will further increase our understanding of the product-specific barriers to trade and as such have substantial policy implications in view of the continued attempts to further enhance free trade and exploit the returns from specialization. More attention should also be devoted to the proximity-concentration trade off. So far, we have considered trade in isolation and thus neglected foreign direct investments as an alternative mode of entering foreign markets. Also for foreign direct investments, the pay-off from considering investments at a disaggregate level is likely to be substantial, although data problems are particularly severe in this research domain. 


\section{References}

Anderson, J.E. (2007): The Incidence of Gravity in General Equilibrium, Paper presented at Conference 'The Gravity Equation - Or: Why the World is Not Flat', Groningen.

Anderson, J.E. and D. Marcouiller (2002): Insecurity and the Pattern of Trade: An Empirical Investigation, Review of Economics and Statistics, 84, pp. 342-352.

Anderson, J.E. and E. Van Wincoop (2003): Gravity with Gravitas: A Solution to the Border Puzzle, American Economic Review, 93, pp. 170-192.

Anderson, J.E. and E. Van Wincoop (2004): Trade Costs, Journal of Economic Literature, 42, pp. 691-751.

Berkowitz, D., J. Moenius and K. Pistor (2006): Trade, Law and Product Complexity, Review of Economics and Statistics, 88, pp. 363-373.

Boisso, D. and M. Ferrantino (1997): Economic Distance, Cultural Distance, and Openness in International Trade: Empirical Puzzles, Journal of Economic Integration, 12, pp. 456484.

Brainard, S.L. (1997): An Empirical Assessment of the Proximity-Concentration Trade-off between Multinational Sales and Trade, American Economic Review, 87, pp. 520-544.

Brakman, S., G. Garita, H. Garretsen and C. Van Marrewijk (2007): Unlocking the Value of Cross-Border Mergers and Acquisitions, Paper presented at Conference 'The Gravity Equation - Or: Why the World is Not Flat', Groningen..

Cairncross, F. (1997): The Death of Distance: How the Communications Revolution Will Change Our Lives, Boston, MA: Harvard Business School Publications.

Davis, D.R., D.E. Weinstein, S.C. Bradford and K. Shimpo (1997): Using International and Japanese Regional Data to Determine when the Factor Abundance Theory of Trade Works, American Economic Review, 87, pp. 421-446.

Deardorff, A.V. (1998): Determinants of Bilateral Trade: Does Gravity Work in a Neoclassical World?, in: Frankel, J.A. (ed.), The Regionalization of the World Economy, Chicago: University of Chicago Press.

Deardorff, A.V. (2004): Local Comparative Advantage: Trade Costs and the Pattern of Trade, Research Seminar in International Economics Discussion Paper, 500, University of Michigan.

De Groot, H.L.F., G.J.M. Linders, P. Rietveld and U. Subramanian (2004): The Institutional Determinants of Bilateral Trade Patterns, Kyklos, 57, pp. 103-123. 
Den Butter, F.A.G. and R.H.J. Mosch (2003): Trade, Trust and Transaction Costs, Tinbergen Institute Discussion Paper, 2003-082/3, Amsterdam-Rotterdam.

Disdier, A. and K. Head (2008): The Puzzling Persistence of the Distance Effect on Bilateral Trade, Review of Economics and Statistics, 90, pp. 37-48.

Dixit, A.K. (2004): Lawlessness and Economics: Alternative Modes of Governance, The Gorman Lectures in Economics, Princeton and Oxford: Princeton University Press.

Eichengreen, B. and D.A. Irwin (1998): The Role of History in Bilateral Trade Flows, in: Frankel, J.A. (ed.), The Regionalization of the World Economy, pp. 33-57, Chicago and London: The University of Chicago Press.

Elsass, P.M. and J.F. Veiga (1994): Acculturation in Acquired Organizations: A Force-Field Perspective, Human Relations, 47, pp. 431-453.

Feenstra, R.C. (2004): Advanced International Trade: Theory and Evidence, Princeton and Oxford: Princeton University Press.

Feenstra, R.C., R.E. Lipsey, H. Deng, A.C. Ma and H. Mo (2005): World Trade Flows: 19622000, NBER Working Paper, 11040, Cambridge, MA.

Frankel, J.A. (1997): Regional Trading Blocs in the World Economic System, Washington D.C.: Institute for International Economics.

Friedman, T.L. (2005): The World is Flat, London: Penguin Books Ltd.

Geraci, V.J. and W. Prewo (1977): Bilateral Trade Flows and Transport Costs, Review of Economics and Statistics, 59, pp. 67-74.

Greenwood, M. (1975): Research on Internal Migration in the United States: A Survey, Journal of Economic Literature, 13, pp. 397-433.

Guiso, L., P. Sapienza and L. Zingales (2004): Cultural Biases in Economic Exchange, NBER Working Paper, 11005, Cambridge, MA.

Head, K. and T. Mayer (2007): Illusory Border Effects: Distance Mismeasurement Inflates Estimates of Home Bias in Trade, Paper presented at Conference 'The Gravity Equation Or: Why the World is Not Flat', Groningen..

Heckman, J.J. (1979): Sample Selection Bias as a Specification Error, Econometrica, 47, pp. $53-161$.

Helpman, E., M. Melitz and S. Yeaple (2004): Export Versus FDI with Heterogeneous Firms, American Economic Review, 94, pp. 300-316.

Helpman, E., M. Melitz and Y. Rubinstein (2007): Estimating Trade Flows: Trading Partners and Trading Volumes, NBER Working Paper, 12927, Cambridge, MA. 
Hofstede, G. (1980): Culture's Consequences: International Differences in Work-Related Values, Beverly Hills, CA: Sage Publications.

Hofstede, G. (2001): Culture's Consequences: Comparing Values, Behaviors, Institutions, and Organizations across Nations, Thousand Oaks, London, New Delhi: Sage Publications.

Isard, W. (1999): Regional Science: Parallels from Physics and Chemistry, Papers in Regional Science, 78, pp. 5-20.

Kaufmann, D., A. Kraay and M. Mastruzzi (2003): Governance Matters III - Governance Indicators for 1996-2002, World Bank Policy Research Department Working Paper, 3106, Washington D.C.

Kogut, B. and H. Singh (1988): The Effect of National Culture on the Choice of Entry Mode, Journal of International Business Studies, 19, pp. 411-432.

Linders, G.J.M. (2006): Intangible Barriers to Trade: The Impact of Institutions, Culture, and Distance on Patterns of Trade, Tinbergen Institute Research Series, 371, Amsterdam: Thela Thesis Academic Publishing Services.

Linders, G.J.M., A.H.L. Slangen, H.L.F. De Groot and S. Beugelsdijk (2005): Cultural and Institutional Determinants of Bilateral Trade Flows, Tinbergen Institute Discussion Paper, 2005-074/3, Amsterdam-Rotterdam.

Linnemann, H. (1966): An Econometric Study of International Trade Flows, Amsterdam: North-Holland Publishing Company.

Martinez-Zarzoso, I., F.D. Nowak-Lehman and S. Vollmer (2007): The Log of Gravity Revisited, CEGE Discussion Paper, 64, Göttingen.

Neal, M. (1998): The Culture Factor: Cross-National Management and the Foreign Venture, Houndmills, UK: MacMillan Press.

Nijkamp, P. and A. Reggiani (1992): Interaction, Evolution and Chaos in Space, Berlin: Springer-Verlag.

Obstfeld, M. and K. Rogoff (2000): The Six Major Puzzles in International Macroeconomics: Is There a Common Cause, NBER Working Paper, 7777, Cambridge, MA.

Olson, M. (1996): Big Bills Left on the Sidewalk: Why some Nations are Rich, and Others Poor, Journal of Economic Perspectives, 10, pp. 3-24.

Parkhe, A. (1991): Interfirm Diversity, Organizational Learning, and Longevity in Global Strategic Alliances, Journal of International Business Studies, 22, pp. 579-601.

Pöyhönen, P. (1963): A Tentative Model for the Volume of Trade between Countries, Weltwirtschaftliches Archiv, 90, pp. 93-99. 
Rauch, J.E. (1999): Networks versus Markets in International Trade, Journal of International Economics, 48, pp. 7-35.

Rauch, J.E. (2001): Business and Social Networks in International Trade, Journal of Economic Literature, 39, pp. 1177-1203.

Rodrik, D. (2000): How Far Will International Integration Go?, Journal of Economic Perspectives, 14, pp. 177-186.

Santos-Silva, J.M.C.S. and S. Tenreyro (2006): The Log of Gravity, Review of Economics and Statistics, 88, pp. 641-658.

Srivastava, R.K. and R.T. Green (1986): Determinants of Bilateral Trade-Flows, Journal of Business, 59, pp. 623-640.

Tinbergen, J. (1962): Shaping the World Economy, New York: The Twentieth Century Fund.

Trefler, D. (1995): The Case of Missing Trade and Other Mysteries, American Economic Review, 85, pp. 1029-1046.

Vella, F. (1998): Estimating Models with Sample Selection Bias: A Survey, Journal of Human Resources, 33, pp. 127-169.

Verbeek, M. (2004): A Guide to Modern Econometrics (2 ${ }^{\text {nd }}$ edition), Chichester, UK: John Wiley \& Sons Ltd.

Wei, S.J. (2000): Natural Openness and Good Government, NBER Working Paper, 7765, Cambridge, MA.

Yeyati, E.L. (2003): On the Impact of a Common Currency on Bilateral Trade, Economics Letters, 79, pp. 125-129. 


\section{Appendix. Description of the dataset}

The variables included in the analysis and their respective sources are as follows:

- $\quad$ For the size of the countries we use the Gross Domestic Product (GDP). Additionally we include a variable for the GDP per capita. Both GDP and GDP per capita are obtained for the year 2000 from the Penn World Table, Mark 6.2.

- $\quad$ The distance between each pair of countries is obtained from the Centre d'Etudes Prospectives et d'Information Internationales (CEPII). This database offers several measures of distance. This study uses the simple distances, which are obtained from the latitudes and longitudes of the city with the largest population count in the country. This distance is measured 'as the crow flies' by the great circle formula and is measured in kilometres. Alternative measures for distance use the capital city rather than the city with the largest population or take the population distributions into account. The city with the largest population is chosen here because it is expected to be a better indicator for economic activity than the capital city.

- The adjacency variable is a dummy which equals 1 when the two countries included in the country pair are adjacent. Countries are considered to be adjacent when they have a land border or a small body of water as a border. The adjacency variable is also obtained from the CEPII database.

- The data on trade blocs are obtained from OECD data. A distinction is made between 24 different trade blocs. A dummy variable is constructed which equals 1 if both countries are a member of at least one mutual trade bloc in the year 2000 and 0 otherwise. The trade blocs considered are: EU, CANUS, NAFTA, APEC, ANDEAN, CACM, MERCOSUR, GR3, LAIA, CARICOM, CBI, EAC, EMCCA, ECOWAS, CMESA, IOC, SADC, ECWA, WAEMU, SACU, ECCGL, ASEAN, GCC and SAARC.

- The instrument we use in the Heckman selection model (see also Section 4.3) is a variable that indicates whether two countries have the same main religion. This dummy variable is constructed using data from the CIA World Factbook. These data are obtained from surveys at different points in time. The surveys are not all taken in the year 2000, but this should not have a significant effect because the main religion of a country is very persistent over time. The CIA World Factbook provides data on the fraction of the population that practice certain religions. Since there are many similar religions, for this study they have been aggregated into seven groups: Buddhists, 
Catholics, Hindus, Jews, Muslims, Orthodox-Christians, and Protestants. For each country the religion practiced by the highest portion of the population is marked as the main religion. The dummy variable is constructed by assigning a value of 1 if the countries have the same main religion and a value of 0 if they do not.

The countries included in the analysis (in alphabetical order) are Argentina, Australia, Austria, Belgium Luxembourg, Brazil, Canada, Chile, China, Colombia, Denmark, Ecuador, Ethiopia, Finland, France, Germany, Ghana, Greece, Hong Kong, Hungary, Indonesia, Iran, Ireland, Israel, Italy, Japan, Kenya, Republic of Korea, Kuwait, Libya, Malaysia, Mexico, Morocco, Netherlands, New Zealand, Nigeria, Norway, Pakistan, Peru, Philippines, Poland, Portugal, Saudi Arabia, India, Singapore, South Africa, Spain, Sweden, Switzerland, Thailand, Turkey, Egypt, United Kingdom, United States of America, Uruguay, and Venezuela. ${ }^{8}$

\footnotetext{
${ }^{8}$ Compared to the set of countries used by Rauch, our sample does not contain Yugoslavia, which did no longer exist in 2000. Algeria, Bolivia, Iceland, Taiwan, Paraguay, Sudan and Tunisia are excluded because of a lack of data on the cultural indicators.
} 